\title{
Molecular Analyses of Early-Onset Gastric Cancer in Brazilian Patients: TP53 Mutations, Cadherin-Catenin and Mucins Proteins Expression
}

\author{
Edaise Maria da Silva ${ }^{1}$, José Humberto Tavares Guerreiro Fregnani ${ }^{2}$, Ghyslaine Martel ${ }^{3}$, \\ Wilson Luiz Costa Jr. ${ }^{4}$, Felipe José Fernández Coimbra ${ }^{4}$, Maria Isabel Waddington Achatz ${ }^{5}$, \\ Pierre Hainaut ${ }^{3}$, Fernando Augusto Soares ${ }^{1}$
}

${ }^{1}$ Department of Anatomic Pathology, Hospital AC Camargo, São Paulo, Brazil; ${ }^{2}$ Research and Teaching Institute, Barretos Cancer Hospital, Barretos, Brazil; ${ }^{3}$ International Agency for Research on Cancer, Molecular Carcinogenesis Group, Lyon, France; ${ }^{4}$ Department of Abdominal Surgery, Hospital AC Camargo, São Paulo, Brazil; ${ }^{5}$ Department of Oncogenetics, Hospital AC Camargo, São Paulo, Brazil.

Email: s.edaise@gmail.com

Received December $8^{\text {th }}, 2012$; revised January $6^{\text {th }}, 2013$; accepted January $13^{\text {th }}, 2013$

\begin{abstract}
Early gastric carcinomas may develop with a molecular profile differing from sporadic carcinomas occurring at a later age. In this study, we analyzed a retrospective series of 88 patients with gastric adenocarcinoma diagnosed before the age of 45 years for the presence of TP53 mutations, clinicopathological features and immunohistochemistry to evaluate the expression of markers considered to be important in gastric carcinogenesis (E-cadherin, $\beta$-catenin, MUC1, MUC2, MUC5AC, MUC6 and p53). The majority of proportion of tumors were diffuse-type (70\%) and advanced stage (56\%). Familial history of cancer was positive in $21 \%$ of the cases. There was a significant association between altered expression of E-cadherin and $\beta$-catenin, and between p53 expression and perineural invasion. TP53 mutations were detected in $14.5 \%$ of evaluated cases, including a germline mutation (p.R337H) in a 12-year-old patient. Overall survival analysis showed significant differences in relation with tumor stage and histopathology. The evaluated biomarkers did not present prognostic value in non-exploratory multivariate analyses. The low frequency of TP53 mutations in this series suggests these alterations are not a major molecular event in gastric cancer occurring at early age, although the identification of a case with germline p.R337H mutation is consistent with the hypothesis that a small proportion of early, apparently sporadic gastric cancer, may be associated with widespread Brazilian founder mutations. Further studies are needed to evaluate the prognostic significance of markers for specific groups of patients according to tumor histology and familial history.
\end{abstract}

Keywords: Early-Onset; Gastric Cancer; Young Patients, Cellular Adhesion; TP53 Mutations

\section{Introduction}

According to the Brazilian National Cancer Institute estimative for 2012, gastric cancer is the fourth most common cancer among men and the sixth among women in Southeast region of Brazil. It is estimated 12,670 new cases of the disease in males and 7,420 new cases in females, accounting for an estimated 13 and 7 new cases per 100,000 per year for men and women, respectively [1]. Its etiology is complex, involving genetic susceptibility, familial predisposition and combinations of dietary and environmental factors that drive the accumulation of genetic alterations associated with increasing genetic instability [2]. Gastric cancer occurs predominantly in older patients with a peak of incidence in the 6th and 7 th decades. Only $2 \%$ to $15 \%$ of patients diagnosed with this disease are younger than 45 years, and these cases are defined as early-onset gastric cancer (EOGC) [3-5]. According to recent studies, these patients are thought to develop gastric carcinomas with a molecular genetic profile differing from that of sporadic tumors occurring at a later age. A prominent molecular mechanism is biological alterations in the E-cadherin/catenin adhesion complex. Abnormalities in this adhesion complex could lead to Wnt signaling pathway activation and consequently to the tumor progression and metastasis [6,7]. Loss of function mutations in the CDH1 gene encoding E-cadherin has been shown to be the main genetic basis of Hereditary Diffuse Gastric Cancer (HDGC) [8]. Studies have suggested that mucin alterations can be regarded as molecular biomarkers of malignant transformation of the 
gastric mucosa. Gastric carcinomas were found to present a higher level of MUC1 expression than normal mucosa, decreased expression of mucins that are normally expressed in normal gastric mucosa (MUC5AC and MUC6), and expression of the intestinal mucin MUC2 $[9,10]$. Previously, our group has reported the results of a retrospective study evaluating a series of 515 tumors from patients with gastric adenocarcinoma, divided into two groups according to age $(\leq 40$ and $>40$ years) in order to compare the clinicopathological characteristics, immunohistochemical expression of markers related to cellular adhesion (E-cadherin and $\beta$-catenin) and differentiation (MUC1, MUC2, MUC5AC and MUC6), and overall survival. The results showed significant differences between the groups regarding the parameters evaluated, corroborating the hypothesis that young patients develop carcinomas by distinct genetic pathways in comparison to patients with gastric tumors in older age [11].

In addition to HDGC, gastric cancer occurs in other familial diseases with inherited cancer predisposition such as hereditary non-polyposis colorectal cancer (HNPCC) and, more rarely, in Li-Fraumeni (LFS) syndrome. The only known underlying genetic defect, observed in $30 \%$ of families with Li-Fraumeni features, is germline mutation of the TP53 gene $[12,13]$. In Southeast region of Brazil, a TP53 mutant at codon $337(1010 \mathrm{G} \rightarrow \mathrm{A}$, $\mathrm{R} 337 \mathrm{H}$ ) occurs at a frequency of about 1:300 individuals $(0.3 \%)$, which is much higher than the estimated frequency of other germline TP53 mutations elsewhere in the world $[14,15]$. The frequent occurrence of this mutation is caused by a widespread founder effect [16]. Previous studies in Brazil have shown that p.R337H is present in the germline of subjects from families with a wide spectrum of inherited cancers, compatible with $\mathrm{Li}$ Fraumeni-like patterns, and in subjects who are carriers of germline TP53 mutations in Brazil, the occurrence of gastric cancer appears to be relatively common [17]. Recently, we reported a rare case of p.R337H mutation in a 12 year-old male patient diagnosed with a T4N2M1 gastric adenocarcinoma in our institution [18].

In this study, we have analyzed a series of 88 patients with gastric adenocarcinomas diagnosed before the age of 45 years for the presence of mutations in the TP53 gene. Clinicopathological characteristics were reviewed and immunohistochemical analysis was performed to assess the expression pattern of a panel of biomarkers considered important in gastric carcinogenesis (E-cadherin, $\beta$-catenin, MUC1, MUC2, MUC5AC, MUC6 and p53).

\section{Material and Methods}

\subsection{Samples}

A total of 88 patients diagnosed with gastric adenocarci- noma ( $\leq 45$ years old) that were admitted to Hospital AC Camargo (São Paulo, Brazil) for the management of adenocarcinoma of the stomach between 1988 and 2010 and who provided informed consent for inclusion of their tissues in the institutional tumor bank, were considered eligible for this retrospective study. Formalin-fixed, paraffin wax-embedded (FFPE) tissue and frozen tissue samples from these patients were retrieved from the archival tissue bank of the Anatomic Pathology Department. Details of patients' age and gender, familial history of cancer, location and histological type of tumor, depth of wall invasion $(\mathrm{pT})$, lymph node metastasis $(\mathrm{pN})$, distant metastases $(\mathrm{pM})$, stage of disease were obtained from medical charts. Tumor staging followed the AJCC/ UICC TNM staging manual, 7th edition [19]. Histological typing was based on Laurén's classification [20]. Tumor size was categorized according the medium size of all tumors $(\leq 3 \mathrm{~cm}$ and $>3 \mathrm{~cm}$ ). Follow up data were obtained from the hospital records. Overall survival was defined as the time elapsed between primary treatment and death from gastric cancer or from other causes.

\subsection{Immunohistochemical Analyses}

Immunohistochemistry (IHC) was performed in $3 \mu \mathrm{m}$ thick sections from each FFPE sample block by streptavidin-biotin peroxidase technique, as previously described [11]. The following antibodies were used: DO-7 (DakoCytomation, Denmark) for p53 (1:100 dilution); 36 (BD Transduction) for E-cadherin (1:600); 14 (BD Transduction) for $\beta$-catenin (1:800); and all mucins by Novocastra, UK: MUC1 (1:500), MUC2 (1:1000), MUC5AC (1:500) and MUC6 (1:600). The p53 immunoreactivity was scored as positive when staining was seen in $10 \%$ or more tumor cells. The expression of E-cadherin and $\beta$-catenin in malignant cells was compared with that of non-malignant cells. Only the membrane pattern, which was stained as strongly as normal epithelial cells, was considered as normal. In contrast, the absence of a staining-pattern (loss of staining), cytoplasmic pattern (cytoplasmic staining with loss of membranous expression), and heterogeneous pattern (cytoplasmic staining with preservation of membranous expression) were categorized as altered pattern. Nuclear staining of $\beta$-catenin was also categorized as altered pattern. In the case of mixed patterns in some sections, the classification was based on the dominant pattern. The expression of the mucins MUC1, MUC2, MUC5AC and MUC6 was considered positive if at least $10 \%$ of the neoplastic cells were stained.

\subsection{TP53 Sequencing Analyses}

For FFPE tissues, DNA extraction was carried out using 
the QIAamp Micro Kit (Qiagen), and a DNA extraction with phenol-chloroform protocol was performed for frozen tissues. Genomic DNA was screened for TP53 mutations at IARC, and direct sequencing of genomic DNA was performed according to the protocols described in the IARC TP53 database (http://p53.iarc.fr/). Mutations were screened on both DNA strands and confirmed in an independent PCR product. Tumors were classified as Wild-type or Mutated TP53 and the mutations were categorized according the IARC TP53 database.

\subsection{Statistical Analyses}

All statistical analyses were performed using the SPSS 20.0 (SPSS, Chicago, IL). The chi-square test and Fisher's exact test were used to analyze the association between clinicopathological parameters and molecular biomarkers expression. The five-year overall survival rates were estimated using the Kaplan-Meier method. Non-exploratory multivariate Cox models were performed to evaluate the prognostic value of biomarkers (variables of interest). The pathological stage, age and period of treatment were mandatory adjustable variables. In addition, pathological variables with a $p$ value less than 0.10 were also tested in the model (perineural and lymphatic invasion). The level of significance was set at $5 \%$.

\section{Results}

Of the 88 patients $(12$ - 45 years old, mean age of 34.6 years) included in this study, $19(21.6 \%)$ were 30 years old or younger. Table 1 summarizes the frequencies distribution of the clinicopathological variables and biomarkers expression patterns in all patients. There was a higher proportion of male patients, and $21.1 \%$ of the patients reported familial history of cancer. Most tumors were of advanced stage disease and diffuse-type gastric tumors. Similar distributions with respect to perineural and lymphatic involvement were observed, but only $14 \%$ of the cases presented vascular involvement. The association between p53 and the biomarkers expression pattern and the clinicopathological features (Table 2) showed that the frequency of perineural invasion was higher in cases with $\mathrm{p} 53$ positivity $(\mathrm{p}=0.01)$. MUC1 positivity was significantly associated with p53 expression. No significant difference between the expression of p53 and the other biomarkers was observed.

TP53 mutations were detected in 11 of $76(14.5 \%)$ of the evaluated cases. The age of the patients ranged from 12 to 40 years old with a predominance of male patients. Twelve out 88 patients were not considered for the sequencing analyses due to insufficient DNA quality precluding the complete analysis of all TP53 exons. Clinicopathological features, immunohistochemical expres-
Table 1. Clinicopathological characteristics and biomarkers expression of patients with early-onset gastric cancer.

\begin{tabular}{|c|c|c|}
\hline Variables & Categories & $\mathbf{N}(\%)$ \\
\hline \multirow{2}{*}{ Gender } & M & $56(57.7)$ \\
\hline & $\mathrm{F}$ & $41(42.3)$ \\
\hline \multirow{2}{*}{ Familial history of cancer } & $\mathrm{N}$ & $60(78.9)$ \\
\hline & $\mathrm{Y}$ & $16(21.1)$ \\
\hline Depth of invasion & $\mathrm{T} 1$ & $19(22.6)$ \\
\hline \multirow[t]{3}{*}{$\mathrm{pT}$} & $\mathrm{T} 2$ & $18(21.4)$ \\
\hline & $\mathrm{T} 3$ & $43(51.2)$ \\
\hline & $\mathrm{T} 4$ & $4(4.8)$ \\
\hline Lymph node metastasis & Negative & $37(44)$ \\
\hline $\mathrm{pN}$ & Positive & $47(56)$ \\
\hline Distant metastasis & Negative & $68(81.0)$ \\
\hline $\mathrm{pM}$ & Positive & $16(19.0)$ \\
\hline Histological classification & Diffuse & $61(69.3)$ \\
\hline \multirow[t]{2}{*}{ (Laurén) } & Intestinal & $17(19.3)$ \\
\hline & Mixed & $10(11.4)$ \\
\hline \multirow{2}{*}{ Perineural involvement } & Negative & $46(53.5)$ \\
\hline & Positive & $40(46.5)$ \\
\hline \multirow{2}{*}{ Vascular involvement } & Negative & $74(86.0)$ \\
\hline & Positive & $12(14.0)$ \\
\hline \multirow{2}{*}{ Lymphatic involvement } & Negative & $47(54.6)$ \\
\hline & Positive & $39(45.3)$ \\
\hline \multirow{4}{*}{ Tumor location } & Cardia & $8(10.2)$ \\
\hline & Body & $33(42.3)$ \\
\hline & Antrum & $29(37.2)$ \\
\hline & Linitis & $8(10.2)$ \\
\hline \multirow{2}{*}{ Tumor size } & $\leq 3 \mathrm{~cm}$ & $25(53.2)$ \\
\hline & $>3 \mathrm{~cm}$ & $22(46.8)$ \\
\hline \multirow{2}{*}{ E-cadherin } & Altered & $41(55.4)$ \\
\hline & Membranous & 33 (44.6) \\
\hline \multirow{2}{*}{$\beta$-catenin } & Altered & $42(56.0)$ \\
\hline & Membranous & $33(44.0)$ \\
\hline \multirow{2}{*}{ MUC1 } & Negative & $37(74.0)$ \\
\hline & Positive & $13(26.0)$ \\
\hline \multirow{2}{*}{ MUC2 } & Negative & $25(49.0)$ \\
\hline & Positive & $26(51.0)$ \\
\hline \multirow{2}{*}{ MUC5AC } & Negative & $16(32.0)$ \\
\hline & Positive & $34(68.0)$ \\
\hline \multirow{2}{*}{ MUC6 } & Negative & $29(60.4)$ \\
\hline & Positive & 19 (39.6) \\
\hline \multirow{2}{*}{$\mathrm{p} 53$} & $\leq 10 \%$ & $38(50.7)$ \\
\hline & $>10 \%$ & $37(49.3)$ \\
\hline
\end{tabular}


Table 2. Association between p53 and biomarkers expressions and clinicopathological features in early-onset gastric cancer.

\begin{tabular}{|c|c|c|c|c|}
\hline \multirow{3}{*}{ Variables } & \multirow{3}{*}{ Categories } & \multicolumn{2}{|c|}{ p53 expression } & \multirow{3}{*}{ p value } \\
\hline & & $\leq 10 \%$ & $>10 \%$ & \\
\hline & & n $(\%)$ & n (\%) & \\
\hline \multirow{2}{*}{ Gender } & Male & $18(42.9)$ & $24(57.1)$ & \multirow{2}{*}{0.06} \\
\hline & Female & $20(60.6)$ & $13(39.4)$ & \\
\hline \multirow{2}{*}{ Familial history of cancer } & No & $26(51.0)$ & $25(49.0)$ & \multirow{2}{*}{1} \\
\hline & Yes & $6(46.2)$ & $7(53.8)$ & \\
\hline Depth of invasion & $\mathrm{T} 1 / \mathrm{T} 2$ & $17(58.6)$ & $12(41.4)$ & \multirow{2}{*}{0.47} \\
\hline pT & $\mathrm{T} 3 / \mathrm{T} 4$ & $20(47.6)$ & $22(52.4)$ & \\
\hline Lymph node metastasis & Negative & $16(55.2)$ & $13(44.8)$ & \multirow{2}{*}{0.81} \\
\hline $\mathrm{pN}$ & Positive & $21(50.0)$ & $21(50.0)$ & \\
\hline Distant metastasis & Negative & $29(52.7)$ & $26(47.3)$ & \multirow{2}{*}{1} \\
\hline $\mathrm{pM}$ & Positive & $8(50.0)$ & $8(50.0)$ & \\
\hline Histological classification & Diffuse & $26(52.0)$ & $24(48.0)$ & \multirow{3}{*}{1} \\
\hline \multirow[t]{2}{*}{ (Laurén) } & Intestinal & $7(41.2)$ & $10(58.8)$ & \\
\hline & Mixed/Unclassified & $5(62.5)$ & $3(37.5)$ & \\
\hline \multirow{2}{*}{ Perineural involvement } & Negative & $24(66.7)$ & $12(33.3)$ & \multirow{2}{*}{0.01} \\
\hline & Positive & $13(35.1)$ & $24(64.9)$ & \\
\hline \multirow{2}{*}{ Vascular involvement } & Negative & $32(52.5)$ & $29(47.5)$ & \multirow{2}{*}{0.54} \\
\hline & Positive & $5(41.7)$ & $7(58.3)$ & \\
\hline \multirow{2}{*}{ Lymphatic involvement } & Negative & $20(52.6)$ & $18(47.4)$ & \multirow{2}{*}{0.81} \\
\hline & Positive & $17(48.6)$ & $18(51.4)$ & \\
\hline \multirow{4}{*}{ Tumor location } & Cardia & $1(20.0)$ & $4(80.0)$ & \multirow{4}{*}{0.05} \\
\hline & Body & $13(46.4)$ & $15(53.6)$ & \\
\hline & Antrum & $17(60.7)$ & $11(39.3)$ & \\
\hline & Linitis & $3(50.0)$ & $3(50.0)$ & \\
\hline \multirow{2}{*}{ Tumor size } & $\leq 3 \mathrm{~cm}$ & $12(57.1)$ & $9(42.9)$ & \multirow{2}{*}{0.22} \\
\hline & $>3 \mathrm{~cm}$ & $11(50.0)$ & $11(50.0)$ & \\
\hline \multirow{2}{*}{ E-cadherin } & Altered & $18(45.0)$ & $22(55.0)$ & \multirow{2}{*}{0.16} \\
\hline & Membranous & $15(51.7)$ & $14(48.3)$ & \\
\hline \multirow{2}{*}{ b-catenin } & Altered & $18(43.9)$ & $23(56.1)$ & \multirow{2}{*}{0.13} \\
\hline & Membranous & $16(55.2)$ & $13(44.8)$ & \\
\hline $\mathrm{MUC1}$ & Negative & $18(50.0)$ & $18(50.0)$ & 007 \\
\hline & Positive & $2(15.4)$ & $11(84.6)$ & \\
\hline MUC? & Negative & $10(41.7)$ & $14(58.3)$ & \\
\hline $1010<2$ & Positive & $10(38.5)$ & $16(61.5)$ & 0.22 \\
\hline MUUC5 $5 C$ & Negative & $6(37.5)$ & $10(62.5)$ & 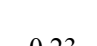 \\
\hline MUU SAC & Positive & $14(42.4)$ & $19(57.6)$ & 0.23 \\
\hline MUC6 & Negative & $12(41.4)$ & $17(58.6)$ & 023 \\
\hline (1) & Positive & $7(38.9)$ & $11(61.1)$ & $0.2 J$ \\
\hline
\end{tabular}


sion of the biomarkers and description of the detected mutations in these eleven cases are listed in Table 3. Of these mutations, three were silent (at codons 216, 289 and 355) and seven were missense (codons 175, 274, 301, $365,380,385$ and 337). A TP53 mutation at codon 337 $(1010 \mathrm{G} \rightarrow \mathrm{A}, \mathrm{R} 337 \mathrm{H})$ was detected in the tumor sample of a 12 year-old male patient diagnosed with advanced gastric adenocarcinoma. This rare occurrence was recently published as a Case Report [18].

In this series, 43 patients were alive with no evidence of disease and four were alive with the disease at the time of evaluation. Thirty-seven patients had died from the disease and three from other causes not connected with gastric cancer. Follow-up ranged from six days to 303.42 months, with a median of 43.5 months.

Univariate analysis (Table 4) showed that patients with advanced-stage disease $(\mathrm{p}<0.001)$, perineural $(\mathrm{p}=$ 0.003 ) and lymphatic invasion ( $p<0.001$ ), and MUC5AC negativity $(p=0.005)$ had a worse survival rate. For the non-exploratory multivariate analysis (Table 5) the adjustable variables for each model were the pathologic stage (I + II vs. III + IV), period of treatment (before 2000 vs. as of 2000) and age (continuous variable). The confidence interval was $95 \%$. None of the biomarkers was found to be independent prognostic factors of survival for the patients with gastric cancer.

\section{Discussion}

Current evidences on the epidemiological and clinicopathological features of gastric cancer in patients younger than 45 years old (defined as early-onset gastric cancer) have suggested that these cancers have distinct molecular and pathological profiles. Despite geographic or ethnic variations, common characteristics of EOGC including female predominance, tumor located at the oesophagogastric junction and in the fundus, diffuse growth types, undifferentiated histology (particularly signet-ring cell carcinoma), and advanced stage and poor prognosis. These characteristics are different from those of older patients $[5,21,22]$.

In our series, there was a predominance of male patients $(57.7 \%)$ and tumor located in the body and antrum regions, which is consistent with other studies [23,24]. Tumor location has been shown to be an independent prognostic factor in gastric carcinoma, with proximal carcinomas (including the gastric cardia and oesophagogastric junction junction) having a poorer prognosis than distal cancers [25], but this observation was not confirmed in the present study. It has been reported that the poor prognosis of patients with EOGC was due to late diagnosis and advanced disease stage, however some studies have shown that this delay did not interfere in the patient survival [26]. Furthermore, several studies showed

Table 3. Description of clinicopathological features and biomarkers expression of cases presenting TP53 mutations.

\begin{tabular}{|c|c|c|c|c|c|c|c|c|c|c|c|c|c|c|c|c|c|c|}
\hline 己ِ & $\begin{array}{l}5 \\
\sum \\
n \\
2 \\
k\end{array}$ & $\begin{array}{l}\overline{\vec{v}} \\
\stackrel{0}{0} \\
\stackrel{0}{0}\end{array}$ & $\stackrel{8}{\&}$ & 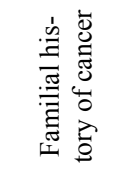 & 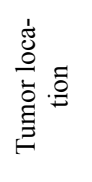 & $\overrightarrow{\mathrm{e}}$ & z & $\sum_{\text {L }}$ & 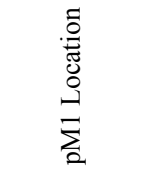 & 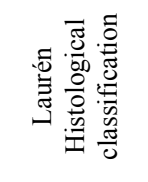 & 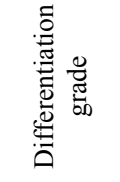 & 卆 & $\sum_{2}^{\infty}$ & $\sum_{2}$ & 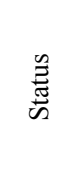 & 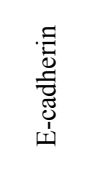 & 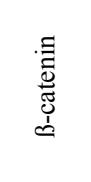 & $\stackrel{n}{n}$ \\
\hline 4 & $\mathrm{R} 175 \mathrm{H}$ & M & 19 & & cardia & 2 & 1 & 0 & & Intestinal & Poorly & Pos & Pos & Pos & NED & Alt & Alt $^{*}$ & pos \\
\hline 7 & A355A & M & 35 & $\begin{array}{l}\text { colorectal, } \\
\text { prostate } \\
\text { and uterus }\end{array}$ & body & 1 & 0 & 0 & & Diffuse & Poorly & Neg & Neg & Neg & NED & Alt & Alt & pos \\
\hline 8 & V274I & F & 36 & & linitis & 3 & 1 & 1 & Liver & Diffuse & Poorly & Pos & Neg & Pos & AWD & Alt & Alt $^{*}$ & pos \\
\hline 9 & $\begin{array}{l}\text { V216V, } \\
\text { F385L }\end{array}$ & $\mathrm{F}$ & 33 & & body & 2 & 0 & 0 & & Diffuse & Poorly & Neg & Neg & Neg & NED & Alt & Memb & pos \\
\hline 18 & $\mathrm{R} 175 \mathrm{H}$ & M & 36 & & linitis & 3 & 3 & 1 & Peritoneum & Diffuse & Poorly & Pos & Pos & Pos & DOD & Memb & Memb & pos \\
\hline 21 & $\mathrm{H} 380 \mathrm{Y}$ & M & 32 & & body & 3 & 2 & 1 & Peritoneum & Diffuse & Poorly & Pos & $\mathrm{Neg}$ & Pos & DOD & Memb & Memb & neg \\
\hline 45 & $\mathrm{H} 365 \mathrm{R}$ & M & 34 & & & 2 & 1 & 0 & & Unclassified & Poorly & $\mathrm{Neg}$ & Neg & Neg & DOD & Alt & $\mathrm{Alt}^{*}$ & neg \\
\hline 51 & L289L & $\mathrm{F}$ & 37 & & body & 1 & 0 & 0 & & Diffuse & Poorly & $\mathrm{Neg}$ & Neg & Neg & NED & Alt & Memb & pos \\
\hline 61 & F385L & M & 31 & & antrum & 2 & 0 & 0 & & Intestinal & Well & Pos & Neg & Neg & DOD & Alt & Alt $^{*}$ & neg \\
\hline 71 & $\begin{array}{l}\text { P301S, } \\
\text { R337H }\end{array}$ & M & 12 & & cardia & 4 & 2 & 1 & & Intestinal & Moderate & Pos & Neg & Pos & DOD & Memb & Memb & pos \\
\hline 89 & $\mathrm{R} 175 \mathrm{H}$ & F & 40 & stomach & linitis & 3 & 3 & 0 & & Diffuse & Poorly & Pos & Neg & Neg & DOD & Alt & Alt $^{*}$ & pos \\
\hline
\end{tabular}

Abbreviations: GCY = sample ID; NED = no evidence of disease; AWD = alive with disease; $\mathrm{DOD}=$ dead of disease; Alt $=$ altered expression; $\mathrm{Memb}=$ membranous expression; ${ }^{*} \mathrm{~b}$-catenin nuclear expression. 
Table 4. Five-year overall survival rates according to clinicopathological features and biomarkers expression in early-onset gastric cancer.

\begin{tabular}{|c|c|c|c|c|}
\hline Variables & Category & $\mathbf{n}$ & 5-yr survival rate (\%) & p value \\
\hline \multirow{2}{*}{ Gender } & M & 47 & 58.5 & \multirow{2}{*}{0.89} \\
\hline & $\mathrm{F}$ & 38 & 61 & \\
\hline \multirow{2}{*}{ Familial history of cancer } & No & 58 & 62.9 & \multirow[b]{2}{*}{0.73} \\
\hline & Yes & 16 & 66.2 & \\
\hline Histologic & Diffuse & 59 & 57.3 & \multirow{3}{*}{0.87} \\
\hline \multirow[t]{2}{*}{ Type } & Intestinal & 16 & 67 & \\
\hline & Mixed/Unclassified & 10 & 60 & \\
\hline \multirow[b]{2}{*}{ pT } & $\mathrm{I} / \mathrm{II}$ & 37 & 91.4 & \multirow[b]{2}{*}{$<0.001$} \\
\hline & III/IV & 47 & 36.2 & \\
\hline \multirow{2}{*}{$\mathrm{pN}$} & Negative & 37 & 88.4 & \multirow{2}{*}{$<0.001$} \\
\hline & Positive & 47 & 37.1 & \\
\hline \multirow{2}{*}{$\mathrm{pM}$} & Negative & 68 & 72.7 & \multirow{2}{*}{$<0.001$} \\
\hline & Positive & 16 & 7.5 & \\
\hline \multirow{2}{*}{ Stage } & Early & 57 & 86.2 & \multirow{2}{*}{$<0.01$} \\
\hline & Advanced & 27 & 4.3 & \\
\hline \multirow{2}{*}{ Perineural invasion } & Negative & 46 & 76.8 & \multirow{2}{*}{0.003} \\
\hline & Positive & 39 & 41.8 & \\
\hline \multirow{2}{*}{ Vascular invasion } & Negative & 73 & 61.6 & \multirow{2}{*}{0.54} \\
\hline & Positive & 12 & 50 & \\
\hline \multirow{2}{*}{ Lymphatic invasion } & Negative & 47 & 77 & \multirow{2}{*}{$<0.001$} \\
\hline & Positive & 38 & 39 & \\
\hline \multirow{2}{*}{ E-cadherin } & Altered & 41 & 62.6 & \multirow[t]{2}{*}{0.26} \\
\hline & Membranous & 30 & 48.1 & \\
\hline \multirow{2}{*}{$\beta$-catenin } & Altered & 41 & 57.4 & \multirow[t]{2}{*}{0.92} \\
\hline & Membranous & 31 & 56.7 & \\
\hline \multirow{2}{*}{ MUC 1} & Negative & 36 & 65.5 & \multirow[t]{2}{*}{0.26} \\
\hline & Positive & 11 & 40 & \\
\hline \multirow{2}{*}{ MUC 2} & Negative & 24 & 57.6 & \multirow[t]{2}{*}{0.85} \\
\hline & Positive & 24 & 59.2 & \\
\hline & Negative & 16 & 30.5 & 0.005 \\
\hline (19) & Positive & 32 & 71 & \\
\hline MUC 6 & Negative & 28 & 51.4 & 0.07 \\
\hline (1) & Positive & 18 & 76.5 & \\
\hline & Negative & 37 & 61.3 & 0.45 \\
\hline Pa & Positive & 35 & 47.4 & \\
\hline$T D 52=0$ & Wild-type & 63 & 60.6 & 0.65 \\
\hline ค & Mutated & 10 & 70 & \\
\hline
\end{tabular}


Table 5. Non-exploratory multivariate models in order to evaluate the prognostic value of biomarkers in early-onset gastric cancer.

\begin{tabular}{|c|c|c|c|c|c|c|}
\hline Model $\left({ }^{*}\right)$ & Number of events & Biomarker & Category & $\mathrm{N}$ & $\mathrm{HR}$ & $95 \% \mathrm{CI}$ \\
\hline \multirow[t]{2}{*}{$\# 1$} & 30 & p53 & $\leq 10 \%$ & 37 & 1 & Reference \\
\hline & & & $>10 \%$ & 34 & 0.6 & $0.3-1.5$ \\
\hline \multirow[t]{2}{*}{$\# 2$} & 28 & E-cadherin & Preserved & 29 & 1 & Reference \\
\hline & & & Altered & 41 & 0.6 & $0.3-1.4$ \\
\hline \multirow[t]{2}{*}{$\# 3$} & 28 & $\beta$-catenin & Preserved & 30 & 1 & Reference \\
\hline & & & Altered & 41 & 0.7 & $0.3-1.6$ \\
\hline \multirow[t]{2}{*}{$\# 4$} & 25 & TP53 & Wild-type & 62 & 1 & Reference \\
\hline & & status & Mutated & 10 & 0.6 & $0.2-2.0$ \\
\hline \multirow[t]{2}{*}{$\# 5$} & 17 & MUC1 & Negative $(<10 \%)$ & 36 & 1 & Reference \\
\hline & & & Positive $(>10 \%)$ & 10 & 0.7 & $0.2-2.2$ \\
\hline \multirow[t]{2}{*}{$\# 6$} & 18 & MUC2 & Negative $(<10 \%)$ & 23 & 1 & Reference \\
\hline & & & Positive $(>10 \%)$ & 24 & 0.9 & $0.3-2.8$ \\
\hline \multirow[t]{2}{*}{$\# 7$} & 16 & MUC6 & Negative $(<10 \%)$ & 27 & 1 & Reference \\
\hline & & & Positive $(>10 \%)$ & 18 & 0.5 & $0.1-2.1$ \\
\hline \multirow[t]{2}{*}{$\# 8$} & 18 & MUC5AC & Negative $(<10 \%)$ & 15 & 1 & Reference \\
\hline & & & Positive $(>10 \%)$ & 32 & 0.7 & $0.2-3.3$ \\
\hline
\end{tabular}

( ) The adjustable variables for each model were: pathologic stage (I + II vs. III + IV), period of treatment (before 2000 vs. as of 2000) and age (continuous variable). $95 \% \mathrm{CI}$ : Confidence interval (95\%).

similar prognosis between young and elderly patients, as long as the disease was diagnosed at an early stage [21,27-29].

There was a predominance of infiltrative tumors and lymph node involvement, as well as the diffuse type tumors (Laurén), which is consistent with other studies $[21,30]$. Lymphatic, vascular, or perineural invasion have been shown to be adverse prognostic factors [25,31]. Regarding the dissemination of gastric adenocarcinoma it has been demonstrated lymphatic spread is more prevalent in gastric cancer than hematogenic spread [32]. In our series, vascular invasion was observed in a small number of cases (14\%) compared to the frequency observed for perineural and lymphatic invasion (49.5 and $45.3 \%$, respectively). The presence of perineural and lymphatic invasion was significantly associated with 5-year overall survival, although these factors were not independent prognostic factors in multivariate analysis.

A recent study performed in our institution compared 515 patients stratified in two groups according to the age ( $\leq 40$ and $>40$ years), and demonstrated a high frequency of alterations in the biomarkers expression in the evaluated gastric carcinomas samples. However, the younger patients presented a significantly higher percentage of diffuse-type tumors, higher frequency of preserved biomarkers and better survival rates than the older patients. These findings supported the hypothesis that young patients develop carcinomas with a different genetic path- way compared to tumors occurring at a later age [11].

Consistent with our previous report [11], the patterns of expression of biomarkers in our series were only marginally altered as compared to normal expression patterns. A significant association between the altered expression of E-cadherin and $\beta$-catenin was observed, confirming the importance of the stability of these two proteins in the maintenance of the functional cellular adhesion system, as reported by other studies $[6,33]$.

In addition to the biomarkers associated to cellular adhesion and differentiation, the expression of p53 as demonstrated by immunohistochemistry was observed in $49.3 \%$ of EOGC. Overexpression of p53 has been reported in $17 \%-91 \%$ of invasive tumors, whereas the reported incidence of TP53 mutations in invasive carcinomas ranges from $0 \%$ to $77 \%$ [34-36].

Clinicopathological features and biomarkers were evaluated according p53 immunopositivity in this study. Positivity for p53 has been related to the proliferating activity and serosal invasion, lymph node metastasis and overall poor prognosis [37,38]. Expression of p53 was also significantly associated with MUC1 expression, independently of overall survival. Furthermore, an association was observed between p53 positivity and perineural invasion, and it was also significantly associated with overall survival. The prognostic significance of perineural invasion in gastric cancer has been previously investigated in few studies with conflicting results [39-41]. 
Assessment of the role of $\mathrm{p} 53$ in gastric cancer in relation to prognosis has produced conflicting results [42-45], largely due lack of consensus in using immunohistochemistry of mutation detection as biomarker.

In 5-year overall survival analyses, tumor characteristics such as pTNM staging, perineural and lymphatic invasion were associated with overall survival in earlyonset gastric cancer. The expression of MUC5AC was significantly associated with better prognosis, consistent with previously reported data [46], but except by pTNM staging, these variables were not found to be independent prognostic factors for patients with gastric cancer diagnosed at a young age.

The frequency of a positive familial history of cancer in young patients points to the need to better identify high-risk individuals for screening [47]. Interestingly, none of the reported familial histories fulfilled the criteria for hereditary diffuse gastric cancer (HDGC) or extra-colonic form of Lynch's syndrome, suggesting the possibility of yet unidentified patterns of inheritance.

TP53 mutations were found to be rare events, occurring in $14.5 \%$ of the evaluated cases, regardless of familial history. This frequency is clearly lower than reported in gastric cancer in general suggesting that mutation of TP53 is not a major event in EOGC in this population. This result suggests that other pathways than p53 may play a prominent role. However, their exact nature remains to be determined. One case of EOGC, the youngest patient in our series, was found to be carrier of p.R337H, a common germline TP53 variant due to a widespread founder effect in the population of Southeast Eastern Brazil. This observation is compatible with data on families carrying this mutation suggesting that gastric cancer is common diagnosis in these families, and underlines the need for including the risk of gastric cancer in surveillance programs for carriers of the p.R337H mutation.

In summary, our results confirm that patients with EOGC have distinct patterns of biomarkers expression and also indicate that TP53 mutation appears to be an infrequent event, adding further evidence that EOGC may represent a specific subtype of gastric cancer from the point of view of molecular mechanisms and, perhaps, genetic risk factors. Although the current series lacked power for assessing multiple biomarkers in multivariate analyses, our observations point to the fact that EOGC has unique molecular features that deserve more detailed investigation in order to identify suitable biomarkers for improving prognosis in this specific group of patients.

\section{Acknowledgements}

The authors thank Edenir Palmero, Amanda Nóbrega, Eloisa Olivieri and Louise Mota for valuable assistance and laboratory support; and Sueli Nonogaki, Severino Ferreira and Carlos Nascimento for technical support. The work of EMS at IARC was partially supported by a UICC International Cancer Technology Transfer Fellowship No. 08-020 and with Federal funds from the National Cancer Institute, National Institutes of Health under Contract NO2-CO-41101; by CNPq (141273/ 2005-4) and FAPESP/CEPID (98/14335-2).

\section{REFERENCES}

[1] J. A. G. da Silva, "Estimate/2012 - Cancer Incidence in Brazil," National Cancer Institute, Rio de Janeiro, 2011. http://www.inca.gov.br/estimativa/2012

[2] A. N. Milne, R. Sitarz, R. Carvalho, et al., "Early Onset Gastric Cancer: On the Road to Unraveling Gastric Carcinogenesis," Current Molecular Medicine, Vol. 7, No. 1, 2007, pp. 15-28. doi:10.2174/156652407779940503

[3] A. N. Milne, R. Carvalho, F. M. Morsink, et al., "EarlyOnset Gastric Cancers Have a Different Molecular Expression Profile than Conventional Gastric Cancers," Modern Pathology, Vol. 19, No. 4, 2006, pp. 564-572. doi:10.1038/modpathol.3800563

[4] R. Carvalho, A. N. Milne, B. P. van Rees, et al., "EarlyOnset Gastric Carcinomas Display Molecular Characteristics Distinct from Gastric Carcinomas Occurring at a Later Age," The Journal of Pathology, Vol. 204, No. 1, 2004, pp. 75-83. doi:10.1002/path.1602

[5] R. Santoro, F. Carboni, P. Lepiane, et al., "Clinicopathological Features and Prognosis of Gastric Cancer in Young European Adults," British Journal of Surgery, Vol. 94, No. 6, pp. 737-742. doi:10.1002/bjs.5600

[6] A. Jawhari, S. Jordan, S. Poole, et al., "Abnormal Immunoreactivity of the E-Cadherin-Catenin Complex in Gastric Carcinoma: Relationship with Patient Survival," Gastroenterology, Vol. 112, No. 1, 1997, pp. 46-54. doi:10.1016/S0016-5085(97)70218-X

[7] M. Tanaka, Y. Kitajima, G. Edakuni, et al., "Abnormal Expression of E-Cadherin and Beta-Catenin May Be a Molecular Marker of Submucosal Invasion and Lymph Node Metastasis in Early Gastric Cancer," British Journal of Surgery, Vol. 89, No. 2, 2002, pp. 236-244.

[8] P. Guilford, J. Hopkins, J. Harraway, et al., "E-Cadherin Germline Mutations in Familial Gastric Cancer," Nature, Vol. 392, No. 6674, 1998, pp. 402-405. doi: $10.1038 / 32918$

[9] C. Carrato, C. Balague, C. De Bolos, et al., "Differential Apomucin Expression in Normal and Neoplastic Human Gastrointestinal Tissues," Gastroenterology, Vol. 107, No. 1, 1994, pp. 160-172.

[10] S. B. Ho, L. L. Shekels, N. W. Toribara, et al., "Mucin Gene Expression in Normal, Pre-Neoplastic, and Neoplastic Human Gastric Epithelium," Cancer Research, Vol. 55, No. 12, 1995, pp. 2681-2690.

[11] E. M. Silva, M. D. Begnami, J. H. Fregnani, et al., "Cadherin-Catenin Adhesion System and Mucin Expression: A 
Comparison between Young and Older Patients with Gastric Carcinoma," Gastric Cancer, Vol. 11, No. 3, 2008, pp. 149-159. doi:10.1007/s10120-008-0468-5

[12] D. Malkin, F. P. Li, L. C. Strong, et al., "Germ Line p53 Mutations in a Familial Syndrome of Breast Cancer, Sarcomas, and Other Neoplasms," Science, Vol. 250, No. 4985, 1990, pp. 1233-1238. doi:10.1126/science. 1978757

[13] J. M. Varley, "Germline TP53 Mutations and Li-Fraumeni Syndrome," Human Mutation, Vol. 21, No. 3, 2003, pp. 313-320. doi:10.1002/humu.10185

[14] F. Lalloo, J. Varley, D. Ellis, A. Moran, L. O'Dair, P. Pharoah and D. G. Evans, "Early Onset Breast Cancer Study Group. Prediction of Pathogenic Mutations in Patients with Early-Onset Breast Cancer by Family History," Lancet, Vol. 361, No. 9363, 2003 pp. 1101-1102. doi:10.1016/S0140-6736(03)12856-5

[15] M. I. Achatz, M. Olivier, C. F. Le, et al., "The TP53 Mutation, R337H, Is Associated with Li-Fraumeni and LiFraumeni-Like Syndromes in Brazilian Families," Cancer Letters, Vol. 245, No. 1-2, 2007, pp. 96-102. doi:10.1016/i.canlet.2005.12.039

[16] E. I. Palmero, L. Schüler-Faccini, M. Caleffi, M. I. Achatz, M. Olivier, G. Martel-Planche, V. Marcel, E. Aguiar, J. Giacomazzi, I. P. Ewald, R. Giugliani, P. Hainaut, P. Ashton-Prolla, "Detection of R337H, a Germline TP53 Mutation Predisposing to Multiple Cancers, in Asymptomatic Women Participating in a Breast Cancer Screening Program in Southern Brazil," Cancer Letters, Vol. 261, No. 1, 2008, pp. 21-25. doi:10.1016/j.canlet.2007.10.044

[17] S. Garritano, F. Gemignani, E. I. Palmero, et al., "Detailed Haplotype Analysis at the TP53 Locus in p.R337H Mutation Carriers in the Population of Southern Brazil: Evidence for a Founder Effect," Human Mutation, Vol. 31, No. 2, 2010, pp. 143-150. doi:10.1002/humu.21151

[18] E. M. da Silva, M. I. Achatz, G. Martel-Planche, et al., "TP53 mutation p.R337H in Gastric Cancer Tissues of a 12-Year-Old Male Child: Evidence for Chimerism Involving a Common Mutant Founder Haplotype: Case Report," BMC Cancer, Vol. 11, 2011, p. 449. doi:10.1186/1471-2407-11-449

[19] L. H. Sobin, M. K. Gospodarowicz and C. Wittekind, "International Union against Cancer (UICC) TNM Classification of Malignant Tumours," 7th edition, Wiley-Liss, New York, 2010, pp. 73-76.

[20] P. Lauren, "The Two Histological Main Types of Gastric Carcinoma: Diffuse and So-Called Intestinal-Type Carcinoma. An Attempt at a Histo-Clinical Classification," Acta Pathologica Microbiologica Scandinavica, Vol. 64, 1965, pp. 46-49.

[21] C. P. Theuer, C. de Virgilio, G. Keese, et al., "Gastric Adenocarcinoma in Patients 40 Years of Age or Younger," The American Journal of Surgery, Vol. 172, No. 5, 1996, pp. 473-476. doi:10.1016/S0002-9610(96)00223-1

[22] H. Medina-Franco, M. J. Heslin and R. Cortes-Gonzalez, "Clinico Pathological Characteristics of Gastric Carcinoma in Young and Elderly Patients: A Comparative Study," Annals of Surgical Oncology, Vol. 7, No. 7, 2000, pp. 515-519. doi:10.1007/s10434-000-0515-X

[23] A. Ramos-De la Medina, N. Salgado-Nesme, G. Torres-Villalobos, et al., "Clinicopathologic Characteristics of Gastric Cancer in a Young Patient Population," Journal of Gastrointestinal Surgery, Vol. 8, No. 3, 2004, pp. 240-244. doi:10.1016/j.gassur.2003.12.009

[24] T. Yokota, N. Takahashi, S. Teshima, et al., "Early Gastric Cancer in the Young: Clinicopathological Study," Australian and New Zealand Journal of Surgery, Vol. 69, No. 6, 1999, pp. 443-446. doi:10.1046/j.1440-1622.1999.01553.x

[25] J. H. van Krieken, M. Sasako and C. J. van de Vele, "Gastric Cancer," In: M. K. Gospodarowicz, D. E. Henson, R. V. P. Hutter, B. O'Sullivan, L. H. Sobin and C. Wittekind, Eds., Prognostic Factors in Cancer, WileyLiss, New York, 2001, pp. 251-265.

[26] T. C. Windham, P. M. Termuhlen, J. Ajani, et al., "Adenocarcinoma of the Stomach in Patients Age 35 Years and Younger: No Impact of Early Diagnosis on Survival Outcome," Journal of Surgical Oncology, Vol. 81, No 3, 2002, pp. 118-124. doi:10.1002/jso.10157

[27] H. Katai, M. Sasako, T. Sano, et al., "Gastric Carcinoma in Young Adults," Japanese Journal of Clinical Oncology, Vol. 26, No. 3, 1996, pp. 139-143. doi:10.1093/oxfordjournals.jjco.a023197

[28] T. Eguchi, Y. Takahashi, M. Yamagata, et al., "Gastric Cancer in Young Patients," Journal of the American College of Surgeons, Vol. 188, No. 1, 1999, pp. 22-26. doi:10.1016/S1072-7515(98)00268-3

[29] B. R. Smith and B. E. Stabile, "Extreme Aggressiveness and Lethality of Gastric Adenocarcinoma in the very Young," Archives of Surgery, Vol. 144, No. 6, 2009, pp. 506-510. doi:10.1001/archsurg.2009.77

[30] M. Rugge, Y. H. Shiao, G. Busatto, et al., "The p53 Gene in Patients under the Age of 40 with Gastric Cancer: Mutation Rates Are Low but Are Associated with a Cardiac Location," Molecular Pathology, Vol. 53, No. 4, 2000, pp. 207-210. doi:10.1136/mp.53.4.207

[31] A. M. Bunt, P. C. Hogendoorn, C. J. van de Velde, et al., "Lymph Node Staging Standards in Gastric Cancer," Journal of Clinical Oncology, Vol. 13, No. 9, 1995, pp. 2309-2316.

[32] M. Bjelovic, P. Pesko, M. Micev, et al., "The Significance of Lymphonodal Micrometastasis in the Patients with Gastric Adenocarcinoma," Acta Chirurgica Iugoslavica, Vol. 52, No. 3, 2005, pp. 21-24. doi:10.2298/ACI0503021B

[33] S. Lim, H. S. Lee, H. S. Kim, et al., "Alteration of ECadherin-Mediated Adhesion Protein Is Common, but Microsatellite Instability Is Uncommon in Young Age Gastric Cancers," Histopathology, Vol. 42, No. 2, 2003, pp. 128-136. doi:10.1046/j.1365-2559.2003.01546.x

[34] C. M. Fenoglio-Preiser, J. Wang, et al., "TP53 and Gastric Carcinoma: A Review," Human Mutation, Vol. 21, No. 3, 2003, pp. 258-270. doi:10.1002/humu.10180

[35] Y. Yamada, T. Yoshida, K. Hayashi, et al., "p53 Gene Mutations in Gastric Cancer Metastases and in Gastric Cancer Cell Lines Derived from Metastases," Cancer Research, Vol. 51, No. 21, 1991, pp. 5800-5805.

[36] P. Correa and Y. Shiao, "Phenotypic and Genotypic Events 
in Gastric Carcinogenesis," Cancer Research, Vol. 54, No. 7, 1994, pp. 1914s-1943s.

[37] Y. Kakeji, D. Korenaga, S. Tsujitani, et al., "Gastric Cancer with p53 Overexpression Has High Potential for Metastasising to Lymph Nodes," British Journal of Cancer, Vol. 67, No. 1, 1993, pp. 589-593. doi:10.1038/bjc.1993.108

[38] S. P. Monig, S. Eidt, T. K. Zirbes, et al., "p53 Expression in Gastric Cancer: Clinicopathological Correlation and Prognostic Significance," Digestive Diseases and Sciences, Vol. 42, No. 12, 1997, pp. 2463-2467. doi:10.1023/A:1018844008068

[39] A. Bilici, M. Seker, B. B. O. Ustaalioglu, et al., "Prognostic Significance of Perineural Invasion in Patients with Gastric Cancer Who Underwent Curative Resection," Annals of Surgical Oncology, Vol. 17, No. 8, 2010, pp. 20372044. doi:10.1245/s10434-010-1027-y

[40] N. Duraker, S. Sişman and G. Can, "The Significance of Perineural Invasion as a Prognostic Factor in Patients with Gastric Carcinoma," Surgery Today, Vol. 33, No. 2, 2003, pp. 95-100. doi:10.1007/s005950300020

[41] A. Tanaka, T. Watanabe, K. Okuno, et al., "Perineural Invasion as a Predictor of Recurrence of Gastric Cancer," Cancer, Vol. 73, No. 3, 1994, pp. 550-555. doi:10.1002/1097-0142(19940201)73:3<550::AID-CNCR $\underline{2820730309>3.0 . \mathrm{CO} ; 2-0}$

[42] Y. Maehara, M. Tomoda, S. Hasuda, et al., "Prognostic Value of p53 Protein Expression for Patients with Gastric
Cancer-A Multivariate Analysis," British Journal of Cancer, Vol. 79, No. 7-8, 1999, pp. 1255-1261. doi:10.1038/sj.bjc.6690201

[43] S. Kubicka, C. Claas, S. Staab, et al., "p53 Mutation Pattern and Expression of c-erbB2 and c-Met in gastric Cancer: Relation to Histological Subtypes, Helicobacter Pylori Infection, and Prognosis," Digestive Diseases and Sciences, Vol. 47, No. 1, 2002, pp. 114-121. doi:10.1023/A:1013275706401

[44] H. E. Gabbert, W. Muller, A. Schneiders, et al., "The Relationship of p53 Expression to the Prognosis of 418 Patients with Gastric Carcinoma," Cancer, Vol. 76, No. 5, 1995, pp. 720-726. doi:10.1002/1097-0142(19950901)76:5<720::AID-CNCR 2820760503>3.0.CO;2-E

[45] H. S. Lee, H. K. Lee, H. S. Kim, et al., "Tumour Suppressor Gene Expression Correlates with Gastric Cancer Prognosis," The Journal of Pathology, Vol. 200, No. 1, 2003, pp. 39-46. doi:10.1002/path.1288

[46] S. E. Baldus, S. P. Monig, V. Arkenau, et al., "Correlation of MUC5AC Immunoreactivity with Histopathological Subtypes and Prognosis of Gastric Carcinoma," Annals of Surgical Oncology, Vol. 9, No. 9, 2002, pp. 887-893. doi:10.1007/BF02557526

[47] J. B. Koea, M. S. Karpeh and M. F. Brennan, "Gastric Cancer in Young Patients: Demographic, Clinicopathological, and Prognostic Factors in 92 Patients," Annals of Surgical Oncology, Vol. 7, No. 5, 2000, pp. 346-351. doi:10.1007/s10434-000-0346-9 